\title{
Empirical quantification of lacustrine groundwater discharge - different methods and their limitations
}

\author{
KARIN MEINIKMANN, GUNNAR NÜTZMANN \& JÖRG LEWANDOWSKI \\ Leibniz-Institute of Freshwater Ecology and Inland Fisheries, Müggelseedamm 310, D-12587 Berlin, Germany \\ meinikmann@igb-berlin.de
}

\begin{abstract}
Groundwater discharge into lakes (lacustrine groundwater discharge, LGD) can be an important driver of lake eutrophication. Its quantification is difficult for several reasons, and thus often neglected in water and nutrient budgets of lakes. In the present case several methods were applied to determine the expansion of the subsurface catchment, to reveal areas of main LGD and to identify the variability of LGD intensity. Size and shape of the subsurface catchment served as a prerequisite in order to calculate long-term groundwater recharge and thus the overall amount of LGD. Isotopic composition of near-shore groundwater was investigated to validate the quality of catchment delineation in near-shore areas. Heat as a natural tracer for groundwater-surface water interactions was used to find spatial variations of LGD intensity. Via an analytical solution of the heat transport equation, LGD rates were calculated from temperature profiles of the lake bed. The method has some uncertainties, as can be found from the results of two measurement campaigns in different years. The present study reveals that a combination of several different methods is required for a reliable identification and quantification of LGD and groundwater-borne nutrient loads.
\end{abstract}

Key words lake; lacustrine groundwater discharge; water balance; heat as a tracer; stable isotopes; groundwater surface water interaction

\section{INTRODUCTION}

Lacustrine groundwater discharge (LGD) is probably the term most difficult to determine in lake water balances. Due to its invisibility, its spatial and temporal variability, and other reasons (Lewandowski et al. 2014, this volume) LGD is mostly neglected and/or handled as a residual in the water balance. However, with high nutrient concentrations LGD might play a key role in lake nutrient budgets and should thus be considered carefully when external nutrient loads of lakes are calculated. For groundwater-borne nutrient loads the amount of groundwater entering a lake in a certain time period is a necessary prerequisite. It might be additionally important to consider spatial heterogeneity of LGD along the shoreline section where groundwater primarily enters the lake. Since nutrient concentrations can also vary along relatively small distances, LGD can drive the actual influence of high nutrient concentrations on the trophic state of a lake: nutrient loads can be low despite high concentrations, when LGD is small in the corresponding reach, while a combination of high concentrations and intense LGD leads to large nutrient loads (Meinikmann et al. 2013).

\section{METHODS}

\section{Study site}

The study site is Lake Arendsee in northeastern Germany (Fig. 1) where intensive research on LGD was done to quantify the impact of groundwater on the water and nutrient budget of the lake. It has a size of $5.1 \mathrm{~km}^{2}$, a maximum depth of $50 \mathrm{~m}$, and a mean depth of about $30 \mathrm{~m}$. Geologic composition of the aquifer material is highly diverse, with values for hydraulic conductivity $\left(k_{\text {sat }}\right)$ ranging from $0.33 \times 10^{-4}$ to $5.69 \times 10^{-4}$, indicating an equivalent spatial heterogeneity in LGD.

\section{Validation of in- and ex-filtration along the shoreline}

The size and shape of the subsurface catchment of Lake Arendsee were determined by interpolation (kriging) of groundwater head measurements in the surrounding of Lake Arendsee (Meinikmann et al. 2013). Hydraulic head contour lines are a prerequisite for the determination of groundwater catchments. However, their reliability strongly depends on the amount of available head observation sites. To validate the expansion of the catchment in the close vicinity of the lake 
(i.e. to separate recharge (infiltration) and discharge (exfiltration) areas) knowledge about isotopic composition of near-shore groundwater can be helpful. Due to evaporation, surface waters have in general a different isotopic signature than groundwater: since water molecules with the lighter isotopes ${ }^{1} \mathrm{H}$ and ${ }^{16} \mathrm{O}$ evaporate faster than water molecules with the heavier isotopes ${ }^{2} \mathrm{H}$ and ${ }^{18} \mathrm{O}$, the latter become enriched in the surface water. Resulting from this, near-shore groundwater in recharge (infiltration) areas should show an isotopic composition that is similar to that of the lake water, but different from discharging (exfiltrating) groundwater. In August 2013, near-shore groundwater was sampled from boreholes hand-drilled to $2 \mathrm{~m}$ below ground and at a distance of 5 to $20 \mathrm{~m}$ from the lake shore. Along the southern shoreline where most groundwater was expected to reach the lake, only a few samples were taken. In the eastern and western parts, as well as along the northern shoreline, sampling density was increased to 200-400 m distance between sampling sites. Additionally, a lake water sample was collected. Furthermore, 11 groundwater observation wells at six different sites south of the lake were also included in the isotopic investigations.

\section{In situ measurement of lacustrine groundwater discharge using heat as a tracer}

Temperature differences between groundwater and surface water can be used as a natural tracer for groundwater-surface water interaction. By solving the heat transport equation (equation (1)), profiles of lake bed temperatures can be analysed for Darcy velocities $\left(q_{z}\right)$ or LGD rates, respectively.

$$
\frac{T(z)-T_{0}}{T_{L}-T_{0}}=\frac{\exp \left(\frac{q_{z} \rho_{f} c_{f}}{K_{f s}} z\right)-1}{\exp \left(\frac{q_{z} \rho_{f} c_{f}}{K_{f s}} L\right)-1}
$$

where $L(\mathrm{~m})$ is the vertical extent of the domain where temperature changes due to LGD, $T(z)$ is the lake bed temperature $\left({ }^{\circ} \mathrm{C}\right)$ at sediment depth $z(\mathrm{~m}), T_{0}$ is the temperature for $z=0$ (i.e. surface water temperature, ${ }^{\circ} \mathrm{C}$ ), $T_{L}$ is the temperature for $z=L$ (i.e. groundwater temperature, ${ }^{\circ} \mathrm{C}$ ), $\rho_{f} \mathcal{C}_{f}$ is the volumetric heat capacity of the fluid $\left(\mathrm{J} \mathrm{m}^{-3} \mathrm{~K}^{-1}\right)$, and $K_{f s}$ is thermal conductivity of the saturated sediment $\left(\mathrm{J} \mathrm{s}^{-1} \mathrm{~m}^{-1} \mathrm{~K}^{-1}\right)$. Schmidt et al. (2006) presented an analytical solution to derive $q_{z}$ from equation (1) by minimizing the root mean squared error (RMSE) between the $n$ measured temperatures of a profile and the related simulated temperatures:

$$
R M S E=\sqrt{\frac{1}{n} \sum_{j=1}^{n}\left[T_{j}-\left(\frac{\exp \left(\frac{q_{z} \rho_{f} c_{f}}{K_{f s}} z_{j}\right)-1}{\exp \left(\frac{q_{z} \rho_{f} c_{f}}{K_{f s}} L\right)-1}\left(T_{L}-T_{0}\right)+T_{0}\right)\right]^{2}}
$$

In September 2011 and July 2012, transects of four lake bed temperature profiles were measured in about $200 \mathrm{~m}$ distances along the southern, western and eastern shoreline. The western and eastern shorelines were not included in the first measurement campaign. A probe consisting of 16 temperature sensors (NTC 10K, TDK EPCOS, Munich, Germany) with a distance of $7 \mathrm{~cm}$ to each other, sampled sediment temperatures down to a depth of $0.98 \mathrm{~cm}$. LGD is focused to nearshore areas of lakes (Kishel and Gerla, 2002). Therefore, the investigations were done close to the shoreline. At each sampling site profiles were measured at $0.5,1,2$ and $4 \mathrm{~m}$ distance to the shoreline. The goal of the measurements was to identify spatial patterns of LGD intensities along the shoreline. For maximal comparability the data of both measurement campaigns were analysed based on the same boundary conditions (i.e. $L$ and $T_{L}$ ). 


\section{RESULTS}

\section{Validation of in- and ex-filtration along the shoreline}

Hydraulic head contour lines indicated a main expansion of the subsurface catchment south of Lake Arendsee, with groundwater also discharging (exfiltrating) along the western and northeastern shoreline (Fig. 1). Lake water recharging (infiltrating into) the aquifer was thus expected to appear along the northwestern and northern shoreline. Contour lines furthermore revealed a large hydraulic gradient at the south southeastern shoreline, indicating high LGD-rates in that area.

Measurements of the stable isotopes of oxygen and hydrogen identified two obviously differing groups of groundwater samples (Fig. 2(a)). Six near-shore samples as well as all samples from the subsurface catchment (ellipse in Fig. 2(a)) showed major differences to the lake water signature (black triangle in Fig. 2(a)). The rest of the samples showed compositions similar to the lake water, or indicated a mixture of lake water and groundwater. In Fig. 2(b) these results are depicted as the difference between lake water $-\delta^{18} \mathrm{O}$ and groundwater- $\delta^{18} \mathrm{O}$. Accordingly, the symbol size in the map represents the similarity of the lake water signature to the groundwater signature. The above-mentioned six samples differing from lake water composition were exclusively taken along the southern part of the lake, while the rest of the near-shore sites are situated along the northern and northwestern shoreline. The results also indicate that the change in isotopic signature happens along a relatively short distance of $200 \mathrm{~m}$ at the western shoreline and $250 \mathrm{~m}$ at the northeastern shoreline, respectively.

\section{In situ measurement of lacustrine groundwater discharge}

In September 2011 LGD rates derived from lake bed temperature profiles ranged between 0 and $131 \mathrm{~L} \mathrm{~m}^{-2} \mathrm{~d}^{-1}$ along the southern shoreline (Fig. 3(a)). Main LGD was indicated to occur along the southeastern shoreline, while along the southwestern shoreline no significant LGD was found from this method. Mean LGD of all measurements was $29 \mathrm{~L} \mathrm{~m}^{-2} \mathrm{~d}^{-1}$. The measurements of July 2012 show a higher mean LGD rate of $44 \mathrm{~L} \mathrm{~m}^{-2} \mathrm{~d}^{-1}$, although the maximum value was slightly lower $\left(122 \mathrm{~L} \mathrm{~m}^{-2} \mathrm{~d}^{-1}\right)$. Highest exfiltration rates $\left(60-122 \mathrm{~L} \mathrm{~m}^{-2} \mathrm{~d}^{-1}\right)$ were found along a $1900-\mathrm{m}$ section at the southern shoreline. At the western and eastern shorelines LGD rates decreased and at some sites even turned to zero (Fig. 3(b)).
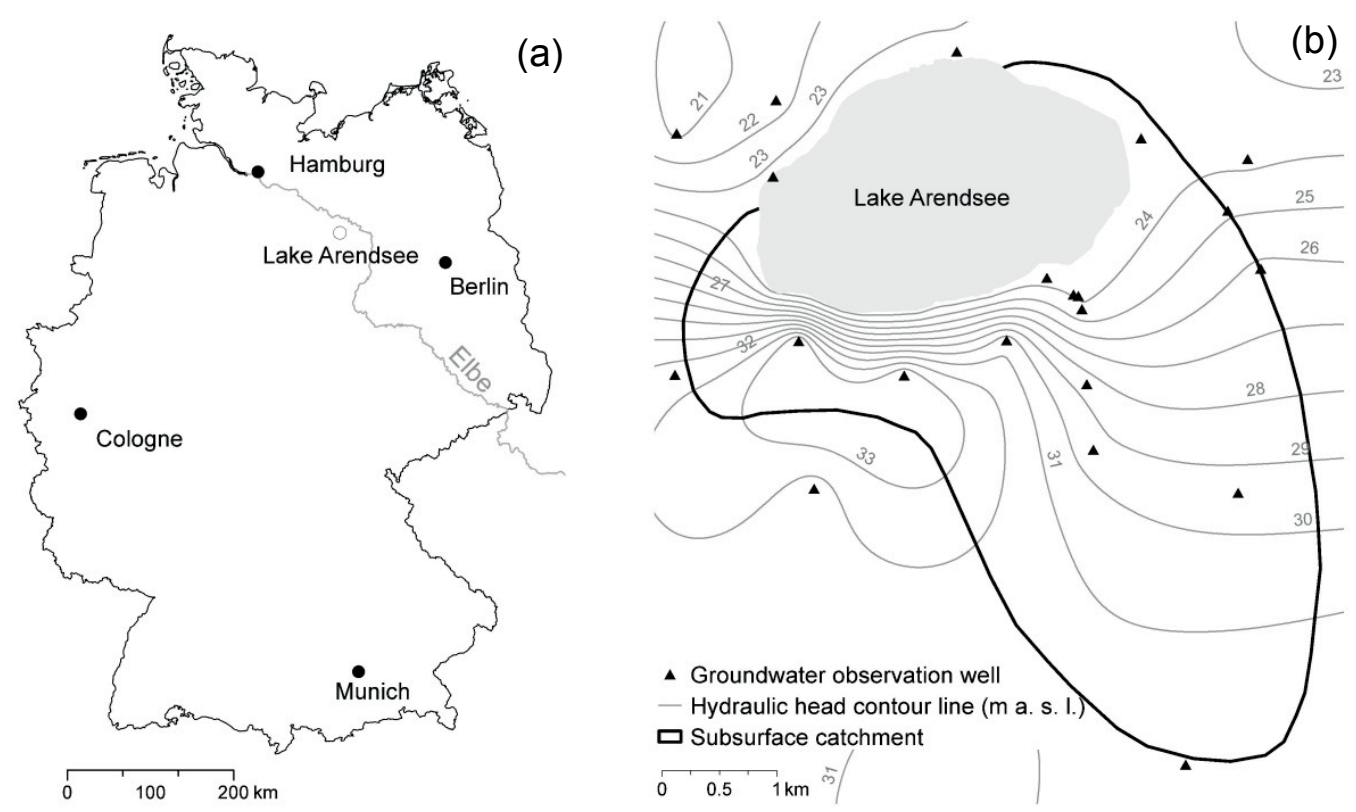

Fig. 1 Location of Lake Arendsee within Germany (a), and hydraulic head contour lines (grey lines) interpolated from head measurements in groundwater observation wells (black triangles) as well as resulting expansion of the subsurface catchment of Lake Arendsee (black line) (b) (Meinikmann et al. 2013). 
(a)

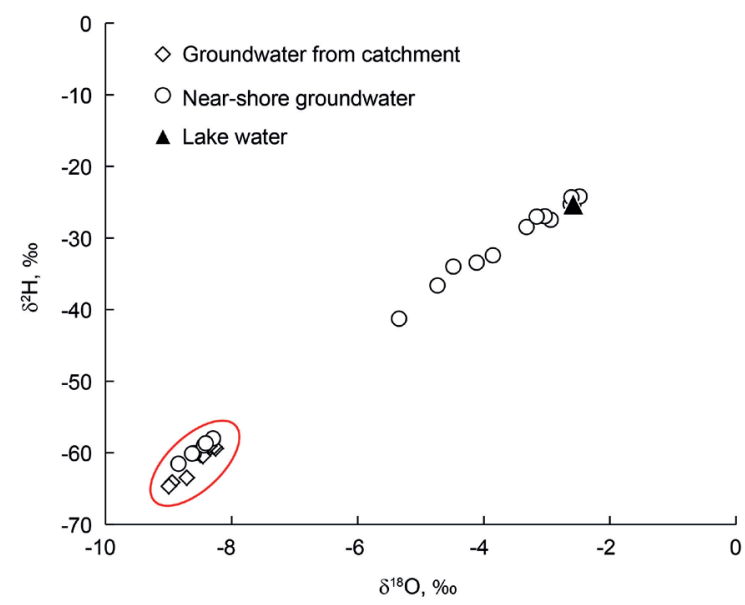

(b)

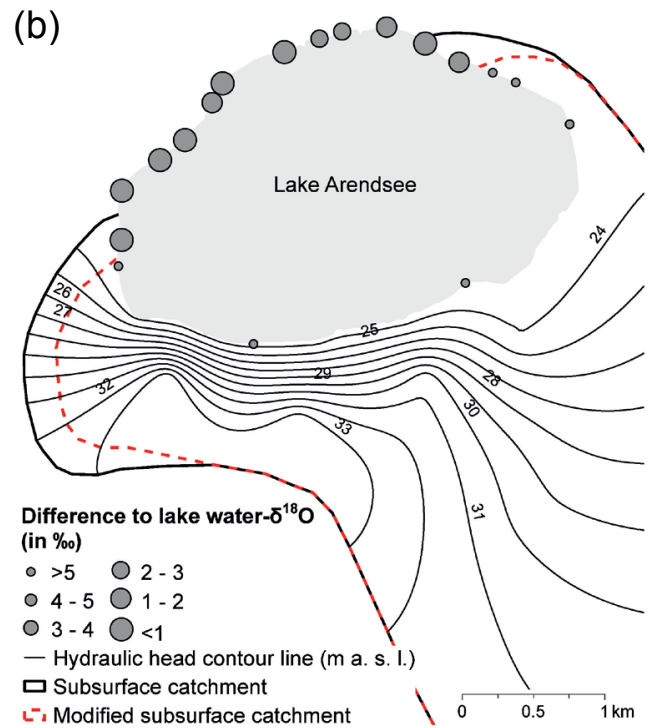

Fig. 2 (a) Values for $\delta^{18} \mathrm{O}$ and $\delta^{2} \mathrm{H}$ for near-shore groundwater (circles), catchment groundwater (rectangles) and lake water (triangle). Two groups of samples are apparent, as there are those which show the isotopic composition of pure groundwater (within ellipse) and those which reveal an influence of lake water that infiltrates into the aquifer. (b) Subsurface catchment of Lake Arendsee (black line) derived from hydraulic head contour lines (grey lines) (Meinikmann et al., 2013). Results of stable isotope measurements are depicted as the difference between lake water- $\delta^{18} \mathrm{O}$ and groundwater- $\delta^{18} \mathrm{O}$ (in \%o). Due to the stable isotope signatures the subsurface catchment of the lake was slightly modified (dashed line).

(a)

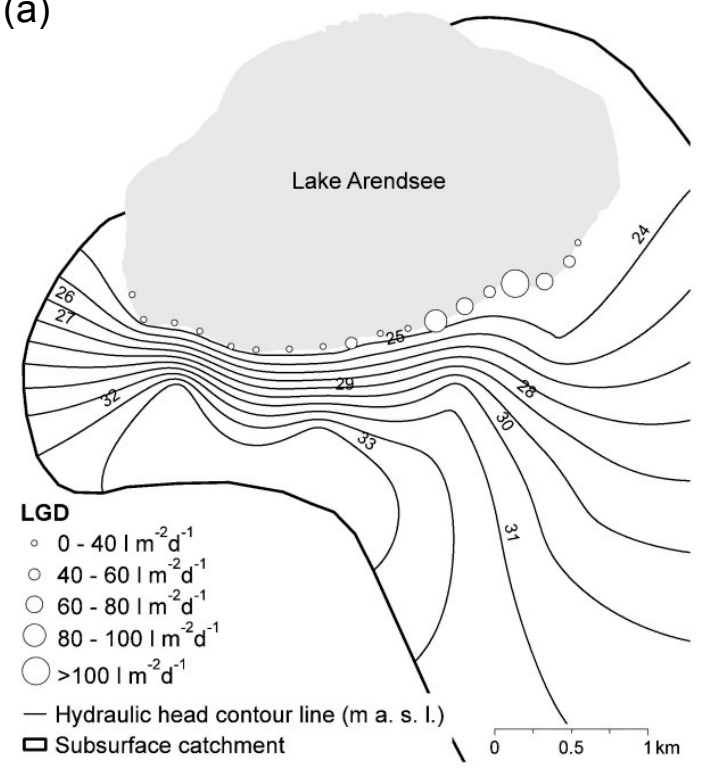

(b)

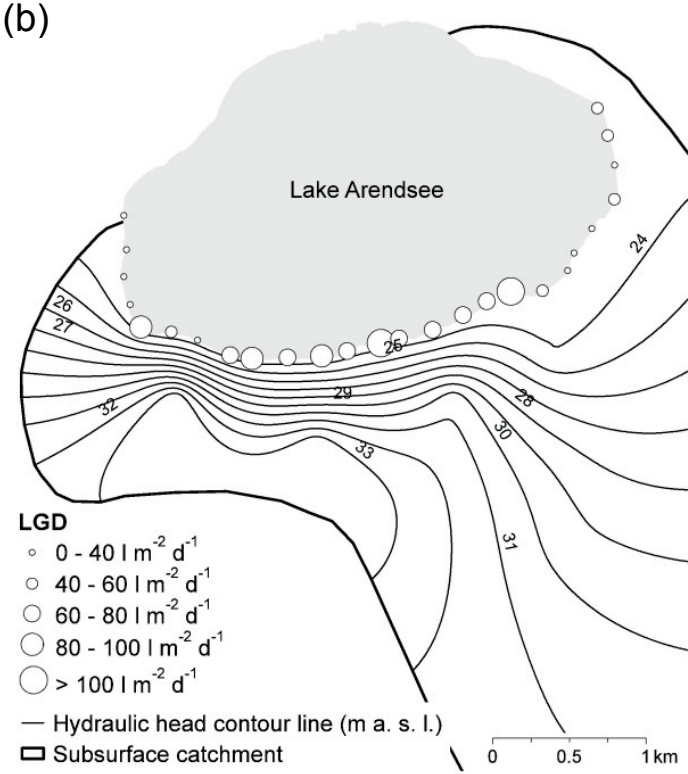

Fig. 3 Maximum rates of lacustrine groundwater discharge (LGD, in $\mathrm{L} \mathrm{m}^{-2} \mathrm{~d}^{-1}$ ) derived from transects of four sediment temperature depth profiles at each observation site in September 2011 (a) and in July $2012(b)$.

Some transects showed a good agreement of LGD rates between the two measurement campaigns in September 2011 and July 2012. Other transects revealed at least the same spatial pattern in both campaigns, even though the absolute values differ (triangles in Fig. 4(a)). There were also transects for which resulting LGD rates differ clearly between the different measurements (Fig. 4(b)). Many of the investigated transects showed a decreasing LGD rate with increasing distance to the shoreline, which is common for isotropic and homogenous sediments (McBride and Pfannkuch 1975). 


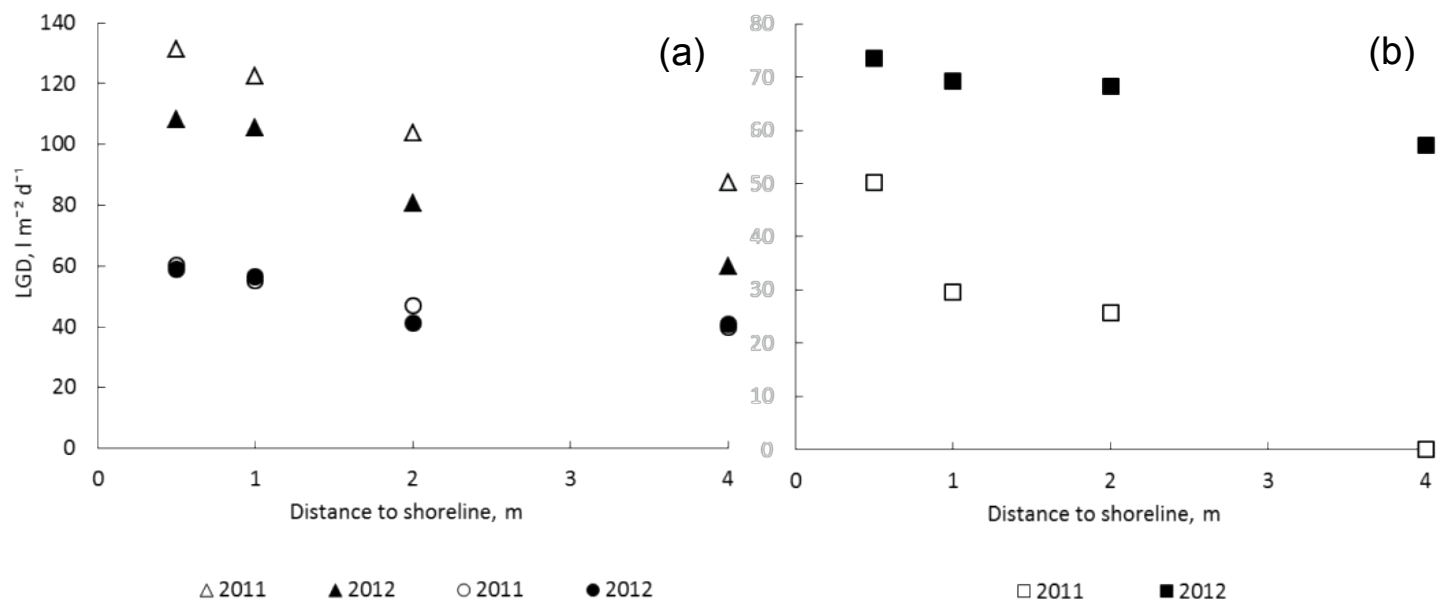

Fig. 4 Lacustrine groundwater discharge (LGD) rates (in $\mathrm{L} \mathrm{m}^{-2} \mathrm{~d}^{-1}$ ) derived from temperature depth profiles of the lake bed sampled in September 2011 (empty symbols) and July 2012 (filled symbols) for three exemplary chosen transects. Circles represent a transect with a good agreement of both measurement, while triangles show a transect which shows the same spatial pattern of LGD with increasing distance to shoreline, but different absolute rates (a). Rectangles present a transect for which neither absolute LGD rates, nor spatial pattern of the two measurements coincide (b).

\section{DISCUSSION}

In the case of Lake Arendsee the isotopic signatures of near-shore groundwater in general supported the delineation of the catchment based on hydraulic head contour lines. Modifying the subsurface catchment due to isotopic composition led to a slightly smaller catchment $(4 \%$ of original size, see also Fig. 2(b)). A zone of mixing between groundwater and lake water due to fast temporal changes from recharging (infiltrating) to discharging (exfiltrating) conditions and vice versa cannot be identified from the data. Nevertheless, it is still possible that a sampling with higher spatial resolution or with a temporal resolution would reveal such zones.

Although the isotopic composition allows the determination of recharging (infiltrating) and discharging (exfiltrating) zones along the shoreline, it is not possible to deduce the quantity of LGD at the observation sites from these data. Therefore, other methods are needed. In the present study heat as a tracer was used to find out about the intensity of LGD along the shoreline. From the two measurement campaigns only the one in 2012 covered the entire LGD section. The results go well along with what was expected due to hydraulic head contour lines and reveal major LGD along the southern shoreline. Additionally, they disclose a spatial heterogeneity of LGD that could not be depicted adequately by hydraulic head contour lines alone. This heterogeneity can have a serious impact on groundwater-borne nutrient loads to the lake. With equal groundwater concentrations the main nutrient input would take place where the main LGD occurs. If spatially high nutrient concentrations occur (e.g. due to point contaminations of the aquifer) a "worst case scenario" has to be considered in which high LGD rates multiply with high concentrations to extraordinary large nutrient loads (Meinikmann et al. 2013). The temperature profiles revealed that in parts of the eastern and western shoreline, where isotopic compositions indicated discharging conditions, almost no flux of groundwater to the lake occurs. This can be attributed to decreased hydraulic gradients and the small expansion of the subsurface catchment.

LGD rates derived from lake bed temperature measurements in September 2011 indicated main groundwater exfiltration along the southeastern shoreline. Compared to the results of 2012 the section of main LGD was shifted slightly eastwards, while at the central southern shoreline no significant LGD occurred. Although the maximum LGD rate was higher than in 2012 the mean value of all calculated rates was clearly lower in $2011\left(44 v s 29 \mathrm{~L} \mathrm{~m}^{-2} \mathrm{~d}^{-1}\right)$ and large parts of the southwestern shoreline did not contribute to LGD. Due to coverage of the entire discharge zone and better agreement to hydraulic head contour lines, the results from 2012 were determined to represent actual hydraulic conditions best. There might be several reasons for the discrepancies of the results of both measurement campaigns: 
(a) Seasonality effects (maximum temperature difference between groundwater and surface water is required).

(b) Wrong estimation, measurement, or spatial upscaling of boundary conditions (e.g. $T_{L}, L$, or $K_{f s}$ in equations (1) and (2)).

(c) Measurement and/or calibration errors.

(d) Small-scale heterogeneities in the lake bed (e.g. changes in $k_{\text {sat }}$ ).

(e) Temporal variations of hydraulic conditions along the shoreline.

(f) Abnormality in temperature profiles that are not caused by LGD (e.g. in coastal areas surface water enters the shore sediments and recirculates before being discharged again; Burnett et al., 2003).

Due to the aforementioned reasons the approach using heat as a tracer has some uncertainties concerning absolute values. Resulting LGD rates should not be used as a basis for upscaling to an overall amount of LGD. Still, they can be used as a powerful tool to gain insight into hydraulic patterns along a lake's shoreline. For example, we combined the results of temperature derived LGD rates with long-term annual groundwater recharge in the catchment of Lake Arendsee (Meinikmann et al. 2013). In the long run it can be assumed that a lake in a steady state receives the same amount of groundwater that is recharged in its catchment. Therefore, the calculation of groundwater recharge was found to be the most reliable method to derive a value for the overall amount of groundwater entering Lake Arendsee. In this context, temperature derived LGD rates were applied as a weighting factor for LGD intensity in shoreline sections. This reduced the influence of uncertainty in temperature-derived LGD rates.

\section{CONCLUSION}

Groundwater-surface water interactions are hard to quantify. Different methods, but also repetitions of the same method, lead to different results. Based on the study presented here we recommend a combination of as many methods as possible to validate the results of one method with those of another approach. The combination of point measurements and integrating approaches (taking the catchment into account) might help to reduce uncertainties. Furthermore, a high spatial resolution of measurements will increase the quality of the results, especially at heterogeneous sites. It might also be advantageous to find out about temporal variations of LGD, e.g. due to seasonal changes of groundwater heads or lake level control.

The current knowledge of eutrophication processes shows that groundwater can be the main reason for ongoing nutrient enrichment of surface waters. And although the investigations of LGD are labour-intensive, it might be of great importance to gain information on spatial quality and overall quantity of groundwater and related nutrient loads entering a lake.

Acknowledgements We thank Adrian Brox, Mareike Noffke and Mads Steiness for help during field campaigns.

\section{REFERENCES}

Burnett, W. C., et al. (2003) Groundwater and pore water inputs to the coastal zone. Biogeochemistry 66(1-2), 3-33. doi: 10.1023/b:biog.0000006066.21240.53

Kishel, H. F. and Gerla, P. J. (2002) Characteristics of preferential flow and groundwater discharge to Shingobee Lake, Minnesota, USA. Hydrol. Processes 16(10), 1921-1934. doi: 10.1002/hyp.363

Lewandowski, J., et al. (2014) From submarine to lacustrine groundwater discharge. In: Complex Interfaces Under Change: Sea - River - Groundwater - Lake (Proceedings of HP2/HP3, IAHS-IAPSO-IASPEI Assembly, Gothenburg, Sweden, July 2013. IAHS Publ. 365, 72-78. IAHS Press, Wallingford, UK (this issue).

McBride, M. S. and Pfannkuch, H. O. (1975) Distribution of seepage within lakebeds. J. Res. US Geol. Surv. 3(5), 505-512.

Meinikmann, K., Lewandowski, J. and Nützmann, G. (2013) Lacustrine groundwater discharge: Combined determination of volumes and spatial patterns. J. Hydrol. 502(0), 202-211. doi: http://dx.doi.org/10.1016/j.jhydrol.2013.08.021

Schmidt, C., Bayer-Raich, M. and Schirmer, M. (2006). Characterization of spatial heterogeneity of groundwater-stream water interactions using multiple depth streambed temperature measurements at the reach scale. Hydrol. Earth Syst. Sci. 10(6), 849-859. 